\title{
Preliminary Design of a Smart Wristband Disinfectant to Help in Covid-19 Fight
}

\author{
Badre El Majid ${ }^{1}\left(\mathbb{D}\right.$, Saad Motahhir ${ }^{2, *} \mathbb{D}$, Aboubakr El Hammoumi ${ }^{3}{ }^{\circ}$, Ambar Lebbadi $^{1}$ \\ and Abdelaziz El Ghzizal ${ }^{3}$ \\ 1 Independent Scientist, Rabat 11100, Morocco; badreov@gmail.com (B.E.M.); \\ Ambar.Lebbadi@gmail.com (A.L.) \\ 2 ENSA, SMBA University, Fez 30000, Morocco \\ 3 Innovative Technologies Laboratory, EST, SMBA University, Fez 30050, Morocco; \\ aboubakr.elhammoumi@usmba.ac.ma (A.E.H.); abdelaziz.elghzizal@usmba.ac.ma (A.E.G.) \\ * Correspondence: saad.motahhir@usmba.ac.ma
}

Received: 10 June 2020; Accepted: 10 July 2020; Published: 14 July 2020

\begin{abstract}
This concept paper describes a device consisting of a disinfectant wristband for the hands of the wearer and objects that the wearer intends to touch. This wristband can be powered automatically by the movement of the user's hand or by solar cells or, if necessary, by a power outlet. It disinfects the surface of the hands and the objects in front of them using an ultraviolet (UV) lamp. Control and monitoring can be carried out automatically or manually, which guarantees complete and effective disinfection. The electronic control system, which is fully integrated into the UV emitter head, regulates the intensity and duration of the UV radiation and also manages the electrical energy. In addition, the wristband can be fitted with an optional watch to improve its decoration and ergonomics. The device in question has a compact, elegant, and practical shape. This hand sanitizing wristband can be an effective tool in the fight against the current COVID-19 pandemic and, in general, help to address the health challenges related to hygiene and disease prevention.
\end{abstract}

Keywords: COVID'19; disinfectant; bracelet

\section{Introduction}

Most people wash their hands as a measure of hygiene and disease prevention, and especially they do so frequently nowadays because of the COVID-19 pandemic. This new virus is spread through respiratory droplets from an infected person to others with whom they are in close contact, such as people living together or providing care [1,2]. The virus can survive on a variety of surfaces, but most cleaning and disinfecting products [3] can destroy it.

It is important to remember the importance of effective and prompt cleaning and disinfection of hands, including objects touched by people's hands, to prevent the spread of contagious diseases. For this reason, devices and systems based on different methods have been developed to clean hands as well as objects. However, these cleaning devices and systems developed so far do not allow cleaning and disinfection of users' hands simultaneously, in a safe, reliable, and effective manner. In [4], the authors present one cleaning device; method and system of cleaning are all combined. It is based on a house that contains a sprayer and a product dispenser, which are associated and communicate with each other. In [5], a disinfection device for portable electronic devices is proposed. This device has a cavity to receive the electronic device to be disinfected. This cavity is equipped with a lid and a ultraviolet (UV) source. The open position of the cover allows the device to be inserted into or removed from the cavity. The closed position of the cover is used during the UV exposure phase. However, these decontamination devices and systems are vulnerable because the user can touch the external 
parts of these sterilization instruments, which may be contaminated, and also because these systems are not portable or completely autonomous. For this purpose, a disinfection device is proposed.

Thus, it was needed to design a portable and lightweight device that provides automatic, integrated, and autonomous cleaning and disinfection of hands and/or objects every time users touch it. This helps to reduce the spread of disease or pandemics, while promoting sterile and clean health environments. The proposed concept concerns a device for cleaning and disinfecting hands and objects touched by the user. It will be composed of a wristband that can be worn on the wrist, an ultraviolet source with a very large degree of liberty, to embrace the whole environment to be disinfected where the touch is accomplished; finally, this wristband will be equipped with a system of production of electrical energy by the movement of the hands of its wearer. The device will be fitted with an electronic control system that will be fully integrated in the UV emitting head, which will increase or decreases the intensity of UV radiation and the duration of this radiation emission on the user's hands and also manage the power supply of the UV lamp. It should be mentioned that the proposed concept is registered as a patent application at "Office marocain de la propriété industrielle et commerciale" under the following number: MA 49542 [6].

The rest of this concept paper is structured as follows: Section 2 presents the design concept of the proposed disinfection device and its operating principle. The challenges for the innovative disinfection system presented are described in Section 3. Finally, Section 4 summarizes the work.

\section{Design Concept}

The concept of the proposed scheme is illustrated in Figures 1-3. The device is a system for disinfecting hands and the objects they touch, as shown in Figure 1, and consists of a wristband that is placed around the wrist of the user's hand. It is equipped with an intelligent electronic system that emits UV rays directly on the palm of the hand and the object in front of it.

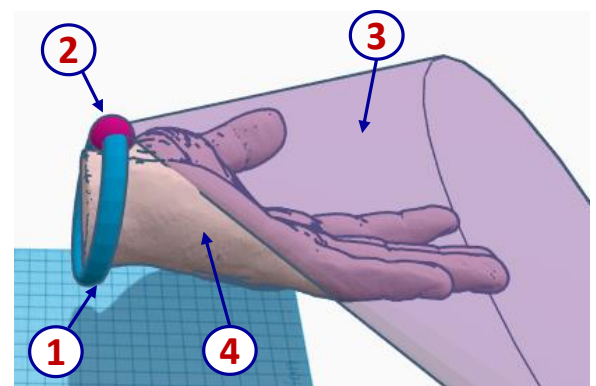

UV radiation emission on the hand

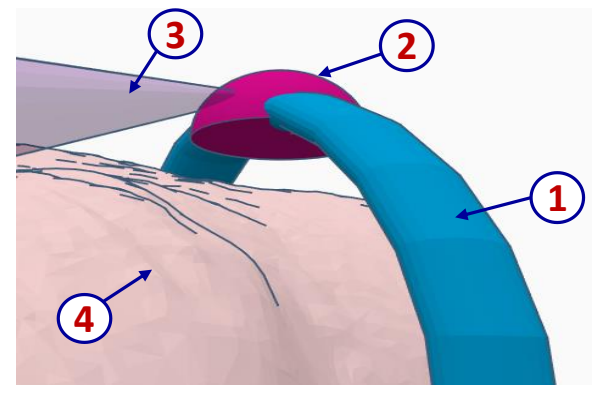
(1) Bracelet
(3) UV radiation
(2) UV-emitting head
(4) User's hand

Figure 1. Coupling between the wristband and ultraviolet (UV) emitter.

The wristband is composed of one or more adjacent coils forming a cylinder, with each coil being empty on the inside to allow the free movement of the magnetic balls; solar cells are arranged on the 
outside of these coils. The UV emitting head consists of a UV lamp embedded in a shell; the shell incorporates an electronic circuit and a battery, with an external power port being attached to the shell.

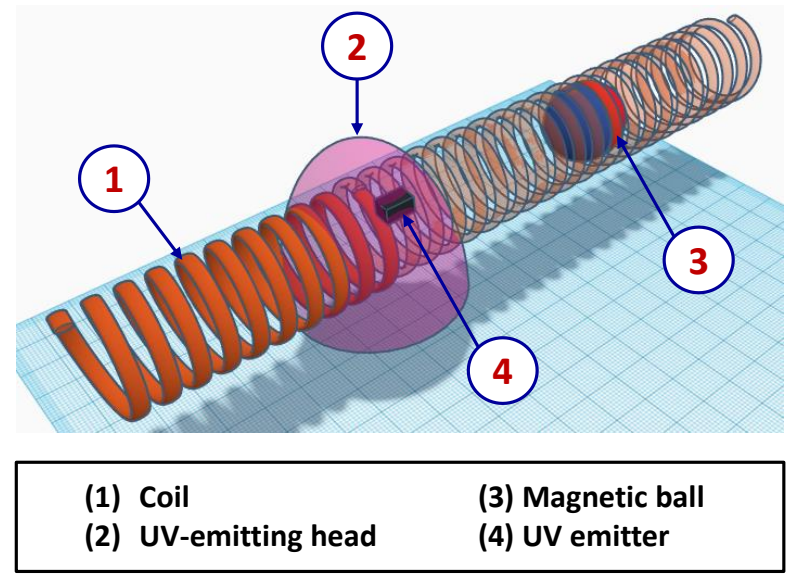

Figure 2. Basis of the motion power generation system.

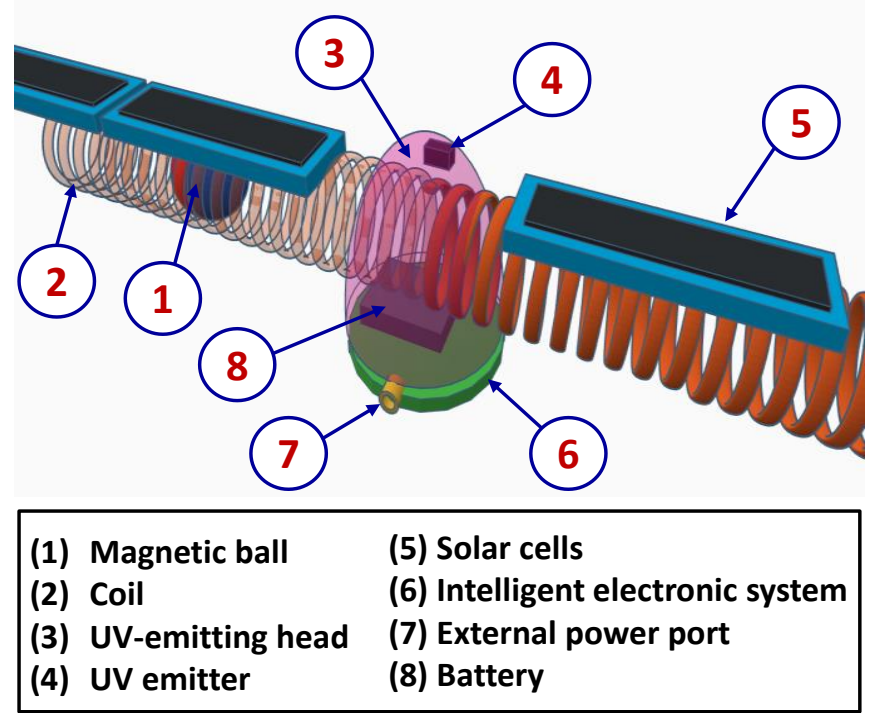

Figure 3. Basis of the power generation system using solar cells and external power supply.

The orientation of the UV emitter, its intensity, and its exposure time are adjustable and controlled by the intelligent electronic system that allows UV radiation to be emitted in any direction. Manual control and on/off buttons will be added. To distribute the UV radiation over the whole of the user's hand and to allow a wide diffusion of these rays on the hands and any object in front of them, we opt for an oval-shaped opening curved outwards, like an eye in front of the UV lamp.

Although powering this system with a small battery seems simpler, we prefer to give this system independence from its electrical energy consumption. To this end, we propose in this invention the following power supply techniques:

(i) Using the electrical energy generated by the movement of the user's hands, the basic principle of which is illustrated in Figure 2. Indeed, when a magnetic ball placed inside the coil moves thanks to the movement of the hands (when the user rubs or slaps his hands), an induced current is generated in the circuit, which then charges a capacitor, which, in turn, discharges; this electrical voltage supplies the UV emitter to be emitted as UV radiation through the small UV lamp. The power can be increased by placing several adjacent coils. With this solution, the UV lamp will be directly supplied with the generated energy. 
(ii) Equipping the system with small solar cells and a battery to store this energy, the behavior will be the same with small solar cells as shown in Figure 3.

(iii) Equipping the system with a port for charging at a power outlet and a battery to store this energy, the behavior will be the same with small solar cells as shown in Figure 3.

The UV emission system will be programmed to automatically shut off after a given time to protect the user's skin and comply with safety standards. As in [7], certain wavelengths of ultraviolet light can inactivate microorganisms, like fungi and viruses, by damaging their DNA or RNA so that they can no longer reproduce.

In addition, the wristband can include as an option a watch to enhance its design and ergonomics. This hand sanitizer wristband is not only convenient to use but also fashionable.

\section{Challenges}

Based on the promising first research results aimed at developing the concept of the innovative disinfection system presented in this concept paper, work is currently underway to improve various aspects and ensure the safety of people during use. This work includes in particular

- Building a mock-up of the UV-emitting head to cover the largest surface area of the palm of the user's hand without disturbing the normal articulation of his hands;

- Testing all the different approaches to electricity supply, which have been presented earlier in this concept paper;

- Testing many UV lamps to identify the most suitable with our system, in a reduced energy consumption with an adapted radiator;

- Determining the optimal dimensions and materials for the wristband;

- Determining the optimal duration and frequency of disinfection to protect the user's skin and meeting safety standards;

- Making a comparison with existing disinfection systems and our proposal concept, in terms of their level of efficiency, cost, and durability;

- Keeping costs as low as possible to ensure that the final product will be accessible to low-income countries.

\section{Conclusions}

The following conclusions can be drawn from the current proposal:

- We present an attractive opportunity to develop new solutions for UV disinfection systems;

- Our proposal has two major advantages; firstly, it will allow direct disinfection of the palms of the user's hands that are in permanent contact with objects contaminated by microbes or viruses, at any time and according to the user's request. Secondly, at the same time, we will disinfect all objects that are susceptible to being touched by the user, as the UV rays will be sent to these objects;

- The movement power supply system can be used for other applications such as a phone charger.

The epidemic crisis related to COVID'19 has had a significant impact on stimulating the development of innovative solutions. Additionally, it is important to get this product out as quickly as possible. Our goal is to provide a new, low-cost solution that can effectively contribute to addressing today's sanitary challenge.

Author Contributions: Conceptualization, B.E.M., A.L. and S.M.; writing—original draft preparation, S.M., B.E.M. and A.E.H.; writing-review and editing, B.E.M. and S.M.; supervision, A.E.G. All authors have read and agreed to the published version of the manuscript.

Funding: This research received no external funding.

Conflicts of Interest: The authors declare no conflict of interest. 


\section{References}

1. Cascella, M.; Rajnik, M.; Cuomo, A.; Dulebohn, S.C.; Di Napoli, R. Features, evaluation and treatment coronavirus (COVID-19). StatPearls 2020. Publishing.

2. Shereen, M.A.; Khan, S.; Kazmi, A.; Bashir, N.; Siddique, R. COVID-19 infection: Origin, transmission, and characteristics of human coronaviruses. J. Adv. Res. 2020, 24, 91-98. [CrossRef] [PubMed]

3. Repici, A.; Maselli, R.; Colombo, M.; Gabbiadini, R.; Spadaccini, M.; Anderloni, A.; Carrara, S.; Fugazza, A.; Di Leo, M.; Galtieri, P.A.; et al. Coronavirus (COVID-19) outbreak: What the department of endoscopy should know. Gastrointest. Endosc. 2020, 92, 192-197. [CrossRef] [PubMed]

4. Adams, D.J. Combined Cleaner Apparatus, System, and Method of Use Thereof. U.S. Patent Application No. 11/780798, 20 July 2007.

5. Cooper, J.; Cannuscio, R.E. Sanitizer for Portable Electronic Devices. U.S. Patent No. 8,481,970, 9 July 2013.

6. El Majid, B.; Motahhir, S.; El Hammoumi, A.; Lebbadi, A.; El Ghzizal, A. Désinfectant Ultra-Violets Intelligent, Portatif et Autonome. M.A. Patent No. 49542, 21 April 2020.

7. Battling Disease with Ultraviolet Light. Available online: https://medicalxpress.com/news/2020-05-diseaseultraviolet.html (accessed on 15 May 2020).

(C) 2020 by the authors. Licensee MDPI, Basel, Switzerland. This article is an open access article distributed under the terms and conditions of the Creative Commons Attribution (CC BY) license (http://creativecommons.org/licenses/by/4.0/). 